1 Zigmond T. Pressures to adhere to treatment: observations on 'leverage' in English mental healthcare. Br J Psychiatry 2011; 199: 90-1.

2 Burns T, Yeeles K, Molodynski A, Nightingale H, Vazquez-Montes M, Sheehan $K$, et al. Pressure to adhere to treatment ('leverage') in English mental healthcare. Br J Psychiatry 2011; 199: 145-50.

3 Buchy L, Ad-Dab'bagh Y, Malla A, Lepage C, Bodnar M, Joober R, et al. Cortical thickness is associated with poor insight in first-episode psychosis. J Psychiatr Res 2011; 45: 781-7.

4 Buchy L, Czechowska Y, Chochol C, Malla A, Joober R, Pruessner J, et al. Toward a model of cognitive insight in first-episode psychosis: verbal memory and hippocampal structure. Schizophr Bull 2010; 36: 1040-9.

5 Buchner F, Firestone M. Where the public peril begins: 25 years after Tarasoff. J Leg Med 2000; 21: 25.

6 Becker T, Kilian R. Psychiatric services for people with severe mental illness across western Europe: what can be generalized from current knowledge about differences in provision, costs and outcomes of mental health care? Acta Psychiatr Scand Suppl 2006; 429: 9-16.

7 Glancy DR, Glancy GD. The case that has psychiatrists running scared: Ahmed v. Stefaniu. J Am Acad Psychiatry Law 2009; 37: 250-6.

8 Glancy GD, Chaimowitz G. Tarasoff warnings result in criminal charges. J Am Acad Psychiatry Law 2003; 31: 524-5.

9 Gutheil TG. In search of true freedom: drug refusal, involuntary medication, and 'rotting with your rights on'. Am J Psychiatry 1980; 137: 327-8.

10 Kress K. Rotting with their rights on: why the criteria for ending commitment or restraint of liberty need not be the same as the criteria for initiating commitment or restraint of liberty, and how the restraint may sometimes justifiably continue after its prerequisites are no longer satisfied. Behav Sci Law 2006; 24: 573-98.

Mansfield Mela, Department of Psychiatry, College of Medicine, University of Saskatchewan, Canada. Email: mansfieldmela@gmail.com

doi: 10.1192/bjp.200.1.81a

Author's reply: Thank you to Drs Scott-Orr and Mela for their interest. It seems to me that there are two issues here. First, should the law be discriminatory between patients with a physical illness and those with a mental illness? I think not and I'm pleased to say the United Nations Convention on the Rights of Persons with Disabilities (2006), to which the UK is a signatory, supports this view. The convention obligates States to (among many other things) 'take all appropriate measures, including legislation, to modify or abolish existing laws, regulations, customs and practices that constitute discrimination against persons with disabilities'. To explain this further, the UN High Commissioner for Human Rights said, ${ }^{1}$

'Legislation authorizing the institutionalization of persons with disabilities on the grounds of their disability without their free and informed consent must be abolished... This should not be interpreted to say that persons with disabilities cannot be lawfully subject to detention for care and treatment or to preventive detention, but that the legal grounds upon which restriction of liberty is determined must be de-linked from the disability and neutrally defined so as to apply to all persons on an equal basis.

Second, should the law (for everyone) favour patient autonomy, medically determined best interest or a mixture?

In other words, either everyone, with the capacity to make the decision, should be permitted to 'die (or rot) with their rights on' or nobody should. Or the authority to overrule capacitous refusal could be based on a neutral factor such as risk to other people. It should not be dependent on the stigma associated with certain terminology (a mental illness diagnosis).

1 United Nations. Annual Report of the United Nations High Commissioner for Human Rights and Reports of the Office of the High Commissioner and the Secretary-General: A/HRC/10/48, 26 January 2009. United Nations, 2009.

Tony Zigmond, Newsam Centre, Leeds LS14 6WB, UK.

email: azigmond@doctors.net.uk

doi: 10.1192/bjp.200.1.82

\section{Family psychoeducation for major depression: randomised controlled trial}

The paper by Shimazu et al ${ }^{1}$ adds robustness to already existing evidence for the role of family psychoeducation in psychiatric disorders. The study has sound methodology (i.e. randomised controlled trial) with adequate masking, in addition to being the first ever study to examine the effect of family psychoeducation for major depressive disorder. The authors describe the possible limitations of the study honestly. A source of funding (Grant-inAid for Scientific Research, Ministry of Health, Labour and Welfare, 2004) is also mentioned. However, there are some issues which should be further looked into. The aim was to examine family psychoeducation in the maintenance treatment of depression.

However, the patients included were either on continuation or maintenance treatment. Patients who are in partial remission cannot be considered as being in a continuation/maintenance phase. ${ }^{2}$ Also it was not mentioned how many patients had single or recurrent episodes (patients with single episodes need not receive maintenance phase treatment). Any other psychiatric comorbidity (substance misuse or personality disorder) in the participants was not mentioned, even though it has treatment implications. The health status and intellectual functioning of the primary family member included in the study was not mentioned, although these might compromise their active participation in psychoeducation sessions. The authors are silent on the ethical clearance of the study. For four caregivers psychoeducation sessions were done in the individual's home and not in group sessions, which were not included in the final analysis and not part of the methodology mentioned - this could also have had an effect on the efficacy of the study. Remission was defined by the authors as a Hamilton Rating Scale for Depression (HRSD) score $<6$, but the normal score is mentioned as $<7$. $^{3}$ The authors have not mentioned the reason for keeping a low score of HRSD in the study. Last, it could be a printing mistake, in the last line of Table 1 it is mentioned that high expressed emotion (as per FMSS) was seen in seven patients in the intervention group and none in the control group, but the results mention that it is seen in six patients in the intervention group and ten in the control group.

1 Shimazu K, Shimodera S, Mino Y, Nishida A, Kamimura N, Sawada K, et al. Family psychoeducation for major depression: randomised controlled trial. Br J Psychiatry 2011; 198: 385-90.

2 American Psychiatric Association. Practice Guideline for the Treatment of Patients with Major Depressive Disorder, Third Edition. APA, 2010.

3 Blacker D. Psychiatric rating scales. In Kaplan and Sadock's Comprehensive Textbook of Psychiatry, Ninth Edition, Volume 1 (eds BJ Sadock, VA Sadock, P Ruiz): 1047. Lippincot Williams and Wilkins, 2009.

Bichitra N. Patra, Department of Psychiatry, Postgraduate Institute of Medical Education and Research, Chandigarh - 160012, India. Email: patrab.aiims@gmail.com; B. N. Subodh, Department of Psychiatry, Postgraduate Institute of Medical Education B. N. Subodh, Departh
and Research, India

doi: 10.1192/bjp.200.1.82a

Author's reply: We thank Patra \& Subodh for their interest in and their very thorough reading of our study. ${ }^{1}$ Most of their questions are factual ones and we are grateful that we have been given an opportunity to clarify them. First, whether to call further treatment of patients in partial or full remission after the fully syndromatic episode, as in our study, continuation/ maintenance treatment is a terminological issue and not a medically substantive one. And we think our usage of the terms is in consonance with the majority of psychiatrists of the world, as for example done by Paykel et al in their famous study of cognitive therapy to prevent relapse after acute episode of major depression. $^{2}$ 
Second, of the 57 patients who entered the trial, 27 had had a single episode of depression and 30 recurrent major depression. Those with their first lifetime major depressive episode received continuation treatment after their acute phase treatment. The comorbidities of our sample included three individuals with substance use disorder, ten with anxiety disorders and one with personality disorder. It is true that we did not methodically check the intellectual or health status of the primary family members but none apparently suffered from serious dysfunction in these regards. We regret the fact that we did not mention the ethics review committee's approval in the published paper. It had been reviewed and approved by the ethic review committee of Kochi Medical School in 2003, prior to the commencement of the study. In addition, it is not true that four caregivers had their psychoeducation sessions individually: only 4 out of 16 sessions for these four family members were conducted individually either in the hospital or at home. Altogether, 4 out of 216 sessions (1.9\%) were individually delivered. We reasoned that in this first-ever efficacy trial of family psychoeducation for major depression, it would be better for us to deliver the best therapy possible. Our definition of remission reflected some arguments that the accepted threshold might be too high to define true remission. ${ }^{3,4}$ Changing the threshold for remission to $7 / 8$, instead of $6 / 7$, made little change to the findings.

Last, we would like to clarify that there were six (25\%) families with high expressed emotion in the intervention group and ten $(33 \%)$ in the control group.

1 Shimazu K, Shimodera S, Mino Y, Nishida A, Kamimura N, Sawada K, et al. Family psychoeducation for major depression: randomised controlled trial. Br J Psychiatry 2011; 198: 385-90.

2 Paykel ES, Scott J, Teasdale JD, Johnson AL, Garland A, Moore R, et al. Prevention of relapse in residual depression by cognitive therapy: a controlled trial. Arch Gen Psychiatry 1999; 56: 829-35.

3 Zimmerman M, Posternak MA, Chelminski I. Is the cutoff to define remission on the Hamilton Rating Scale for Depression too high? J Nerv Ment Dis 2005; 193: $170-5$.

4 Furukawa TA, Akechi T, Azuma H, Okuyama T, Higuchi T. Evidence-based guidelines for interpretation of the Hamilton Rating Scale for Depression. J Clin Psychopharmacol 2007; 27: 531-4.

Shinji Shimodera, Department of Neuropsychiatry, Kochi Medical School, Kochi University, Japan. Email: shimodes@kochi-u.ac.jp

doi: 10.1192/bjp.200.1.82b 